\title{
Cell-mediated immunity in operable bronchial carcinoma: the effect of injecting irradiated autologous tumour cells and BCG
}

\author{
B H R STACK, ${ }^{1} \mathrm{~N}$ MCSWAN, ${ }^{2} \mathrm{~J}$ M STIRLING, ${ }^{3}$ D J HOLE, ${ }^{4}$ D PARRATT, ${ }^{3} \mathrm{~W}$ G S SPILG,${ }^{5}$ \\ C R GILLIS, ${ }^{4}$ I McHATTIE, ${ }^{6}$ A G H GREEN, ${ }^{1}$ R G WHITE, ${ }^{3}$ AND M A TURNER ${ }^{1}$
}

From the Western Infirmary, ${ }^{1}$ Cardiothoracic Unit, Mearnskirk Hospital, ${ }^{2}$ Department of Bacteriology and Immunology, University of Glasgow, ${ }^{3}$ Cancer Intelligence Unit, Ruchill Hospital, ${ }^{4}$ Department of Pathology, Victoria Infirmary, ${ }^{5}$ and Glasgow Institute of Radiotherapeutics and Oncology, Western Infirmary, ${ }^{6}$ Glasgow, $U K$

ABSTRACT In 52 patients undergoing tests of cell-mediated immunity before surgical resection of bronchial carcinoma a positive tuberculin test result was found in $71 \%$ compared with $68 \%$ of age- and sex-matched controls. Sensitisation to DNCB occurred in $52 \%$ of 37 patients but in $78 \%$ of controls. There was depression of lymphocyte transformation by PPD in 19 patients compared with controls $(\mathrm{P}=0.001)$, but there was no difference in lymphocyte transformation by PHA or pokeweed mitogen between 34 patients and controls.

In a pilot study patients were randomly allocated to autograft (eight) or non-autograft (seven) groups. The autograft group were given an intradermal injection of a suspension of irradiated autologous tumour-cells mixed with intradermal BCG on the day of operation. Tests of cell-mediated immunity were repeated two weeks after operation. Five patients in each group received a course of radiotherapy to the mediastinum three weeks after operation.

There was a rise in cutaneous tuberculin reactivity $(P=0.08)$ and total leucocyte count $(\mathrm{P}=0.09)$ in the autograft group postoperatively with a fall in total lymphocyte and $\mathrm{T}$ lymphocyte counts in the non-autograft group $(\mathrm{P}<0.05)$. These differences, however, were not followed by any difference in the frequency of tumour recurrence or the survival rate two years after operation.

The results show that the immunological surveillance mechanism is impaired even in patients with early bronchial carcinoma and that it is possible to overcome postoperative immunological depression with specific immunotherapy combined with BCG. This treatment did not produce any clinical advantage in this small number of patients and the skin lesions caused the patients considerable discomfort.

Early reports have suggested that most forms of immunotherapy have at best a weak action against bronchial carcinoma. Immunotherapy is thus likely to be effective only when the tumour cell population has been substantially reduced by surgery or radiotherapy (Price Evans, 1976). The one advantage of immunotherapy over conventional treatment is that immunologically activated cells can seek out and destroy small residual populations of tumour cells before they can be detected and treated by other means.

Immunotherapy is unlikely to be effective unless immunological function is already depressed. Depression of cell-mediated immunity has been reported in patients with resectable bronchial car- $\omega$ cinoma (Dellon et al, 1975; Coy et al, 1977) and? after surgical operations (Park et al, 1971).

These considerations have led us to investigate immunological function in 52 patients under-going resection of bronchial carcinoma. This paper also describes a pilot study of the effect of injecting irradiated autologous tumour cells with? BCG on 15 of these patients. In these the tumour cell population had been substantially reduced by 
surgery and postoperative irradiation of the mediastinum. Because this was a preliminary study of the feasibility of giving autologous cells with BCG in a limited number of patients, we did not employ a second control group treated with BCG alone.

\section{Methods}

\section{PATIENTS}

Informed consent was obtained from patients undergoing thoracotomy for suspected bronchial carcinoma. The scheme of the pilot trial is shown in fig 1. A tuberculin test and laboratory tests of immunological function were performed a week before operation, at two and ten weeks after operation, and at three-monthly intervals thereafter. At operation, once the surgeon had decided that the tumour and all the visible enlarged lymph nodes could be resected, a card was drawn from an envelope appropriate to the patient's age group and sex that randomly allocated the patient to the autograft or non-autograft group. If the patient was allocated to the autograft group a suspension of cells from his tumour was made according to the method of Anderson et al (1973). The average cell count of the suspension was $14.3 \times$ $10^{6} / \mathrm{ml}$, the volume of the suspension being about $20 \mathrm{ml}$. This was irradiated using a single minimum dose of 12250 rads (H V L $2.5 \mathrm{mmCu}$ ). Provided that a frozen section of the tumour mass confirmed that it was bronchial carcinoma, $3 \mathrm{ml}$ of the irradiated tumour cell suspension was mixed with $0.5 \mathrm{ml}$ of standard intradermal BCG (viable units per ampoule $\left.8-26 \times 10^{6}\right)$. This was injected intradermally into three or four sites on the anterior and lateral surfaces of the thighs on the day of operation. The remainder of the cell suspension was stored at $-70^{\circ} \mathrm{C}$. Further injections of $3 \mathrm{ml}$ of cell suspension were given two and ten weeks after operation.

The average age of the autograft group was 60 and of the non-autograft group 53. The autograft group included one woman and the non-autograft group two. Three patients in each group had lobectomies, the remainder having pneumonec- tomies. Four of the autograft group and five of the non-autograft group had squamous cell carcinoma. Five patients in each group completed a course of supervoltage $x$ ray therapy, 3500 rads tumour dose being given in 16 treatments over 22 days three weeks after operation.

\section{IMMUNOLOGICAL TESTS}

Preoperative immunological tests were carried out in 52 patients, including the 15 from the pilot trial.

\section{Skin tests}

A standard tuberculin test using 10 tuberculin units PPD (Weybridge) was performed in 52 patients before operation. This was considered to be positive if the maximum diameter of the induration exceeded $10 \mathrm{~mm}$ after 48 hours. Thirtyseven patients were sensitised with $2 \%$ DNCB. After more than 10 days a strip consisting of five patches impregnated with serial dilutions of DNCB from 62.5 to $1000 \mu \mathrm{g} / \mathrm{ml}$ was applied to the volar surface of the other forearm. The strip was removed two days later and the reaction graded according to the extent of erythema and oedema produced. Erythema covering the area of the disc treated with $500 \mu \mathrm{g} / \mathrm{ml}$ was taken as a positive reaction.

\section{Laboratory tests}

A $40 \mathrm{ml}$ venous blood sample was taken for estimation of total white cell count, total lymphocyte count, $T$ and $B$ cell numbers, and estimation of lymphocyte transformation by phytohaemagglutinin (PHA), pokeweed, and PPD. Of the heparinised whole blood, $20 \mathrm{ml}$ was separated on FicollTriosil mixture to provide lymphocytes for the estimation of $T$ and $B$ cells by the rosetting technique and for the lymphocyte transformation studies (Mackie et al, 1976). In the rosetting technique 200 cells were counted.

Modifications of the method employed by Mackie et al (1976) for lymphocyte transformation included the number of cells put up in culture and the culture medium. The culture technique employed in this trial used $0.5 \times 10^{6}$ cells per tube

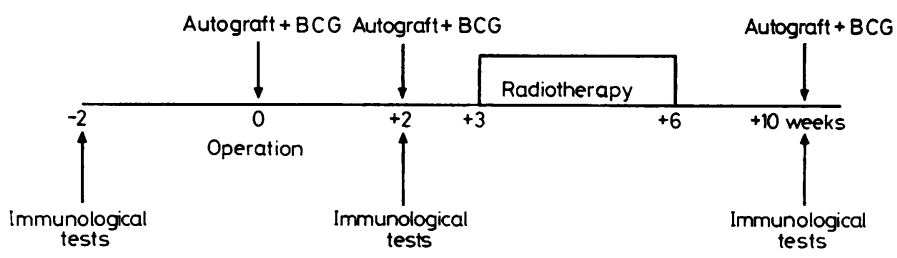

Fig 1 Scheme of pilot trial. 
incubated in Eagle's medium buffered with $2 \%$ Hepes buffer and enriched with $10 \%$ fetal calf serum. The results were compared with those from healthy subjects or non-cancer bearing patients over the age of 40 .

\section{Results}

PREOPERATIVE IMMUNOLOGICAL RESULTS

The results of the preoperative skin tests are given in table 1. There was no difference between the prevalence of positive tuberculin reactions in 52 patients with operable bronchial carcinoma compared with that in controls matched for age and sex taken from the survey of the general population of Renfrew (Hawthorne, 1978, personal communication). Of the 37 patients studied, $52 \%$ developed sensitivity to DNCB compared with $78 \%$ of age- and sex-matched controls suffering from non-malignant pulmonary or cardiac disorders, or both.

Table 1 Prevalence of positive skin reactions to tuberculin and DNCB among patients with bronchial carcinoma and age-and sex-matched controls

\begin{tabular}{lllll}
\hline & $\begin{array}{l}\text { No of } \\
\text { patients } \\
\text { tested }\end{array}$ & $\begin{array}{l}\text { Percentage of } \\
\text { patients with } \\
\text { positive skin } \\
\text { reaction }\end{array}$ & Significance \\
\cline { 2 - 5 } & & $\begin{array}{l}\text { Bronchial } \\
\text { carcinoma } \\
\text { patients }\end{array}$ & $\begin{array}{l}\text { Age- } \text { sex-matched } \\
\text { controls }\end{array}$ & \\
\hline Tuberculin test & 52 & 71 & 68 & NS \\
DNCB test & 37 & 52 & 78 & P $<0.05$ \\
\hline
\end{tabular}

NS $=$ Not significant

Table 2 shows the median lymphocyte transformation ratios for PHA, PPD, and pokeweed before operation in bronchial carcinoma patients compared with those of controls over the age of 40 who were either healthy or suffering from nonmalignant pulmonary disorders other than tuberculosis. Similar results were obtained when PHA and pokeweed were used. Nevertheless there was $\stackrel{\overrightarrow{\vec{S}}}{\stackrel{\overrightarrow{0}}{\circ}}$ significant depression of lymphocyte transform- $\bar{C}$ ation by PPD in patients with operable bronchial 음 carcinoma compared with controls.

EFFECT OF THE AUTOGRAFT OF IRRADIATED TUMOUR CELLS AND BCG

Clinical

The first injection of irradiated tumour cells with $\overrightarrow{\vec{\omega}}$ BCG produced a pyrexia lasting 48 hours in most patients. The local reaction consisted of induration $\vec{x}$ and erythema, which appeared between 48 and $72 \dot{\omega}$ hours after injection and became maximal at $10 \stackrel{\nexists}{.}$ days. The indurated area became necrotic after 0 several weeks and broke down with the formation of ulcers between 5 and $10 \mathrm{~mm}$ in diameter (fig 2). These continued to discharge for three to six $\vec{T}$ months and then healed slowly leaving painless $\mathbb{D}$ scars (fig 3).

The effect of the autograft on survival of patients two years after the completion of the pilot study is shown in fig 4. Five deaths have $\stackrel{0}{ }$ occurred among eight patients in the autograft. group. Four died from tumour recurrence and one from a myocardial infarction. Necropsy on one patient showed a metastasis in the cerebellum but no evidence of local or systemic effects from the immunotherapy. Three out of seven non-autograft $\stackrel{\varnothing}{\complement}$ patients have died, one from postoperative respir- $\overrightarrow{\overrightarrow{0}}$ atory infection and two from tumour recurrence. 3 A fourth non-autograft patient has evidence of mediastinal recurrence of tumour. When patients? dying without evidence of tumour recurrence have been excluded, three patients in each group have remained free of local recurrence and metastases $\ddot{\otimes}$ for two years. Hence the survival rate and the tumour-free incidence is not significantly different between the two groups.

Postoperative immunological tests

The results of immunological tests two weeks $\supset$ after operation in the 15 patients in the pilot trial compared with the preoperative results are given $N$ in table 3. Tuberculin reactivity increased sig-

Table 2 Preoperative lymphocyte transformation ratios in patients and controls

\begin{tabular}{|c|c|c|c|c|c|c|c|}
\hline \multirow[t]{3}{*}{ Mitogen } & \multicolumn{6}{|c|}{ Lymphocyte transformation ratios } & \multirow[t]{3}{*}{ Significance } \\
\hline & \multicolumn{3}{|c|}{ Bronchial carcinoma patients } & \multicolumn{3}{|c|}{ Controls } & \\
\hline & No & Median & Range & No & Median & Range & \\
\hline PHA & 34 & $101 \cdot 0$ & $9-665$ & 58 & 96.5 & $13-335$ & NS \\
\hline Pokewood & 34 & $29 \cdot 0$ & 4-215 & 58 & $30 \cdot 5$ & $5-129$ & NS \\
\hline PPD & 19 & $2 \cdot 0$ & $1-7$ & 35 & $5 \cdot 0$ & $1-21$ & $P=0.001$ \\
\hline
\end{tabular}




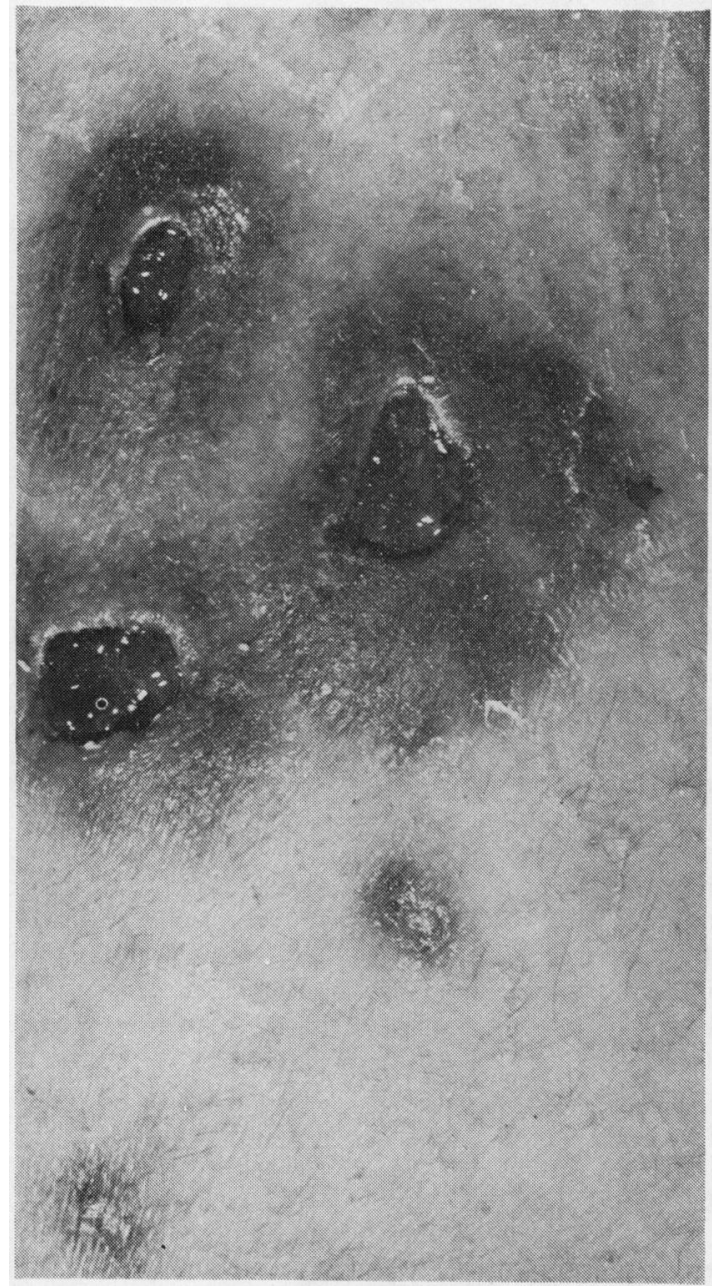

Fig 2 Ulcers on thigh of patient injected with irradiated autologous tumour cells and BCG six months previously.

nificantly in the autograft group who received $0.5 \mathrm{ml}$ of intradermal BCG in addition to the irradiated tumour cells. In two patients with negative preoperative tuberculin tests postoperative conversion occurred in the one autograft patient but not in the one control patient. In the autograft group there was also a rise in total white cell count, while the total lymphocyte count remained steady. In contrast there was no significant change in tuberculin reactivity or total leucocyte count in the control group but in this group the total lymphocyte count and the $T$ lymphocyte count fell. There was no significant change in the lymphocyte transformation ratios for PHA and pokeweed in either group. Lymphocyte transfor-

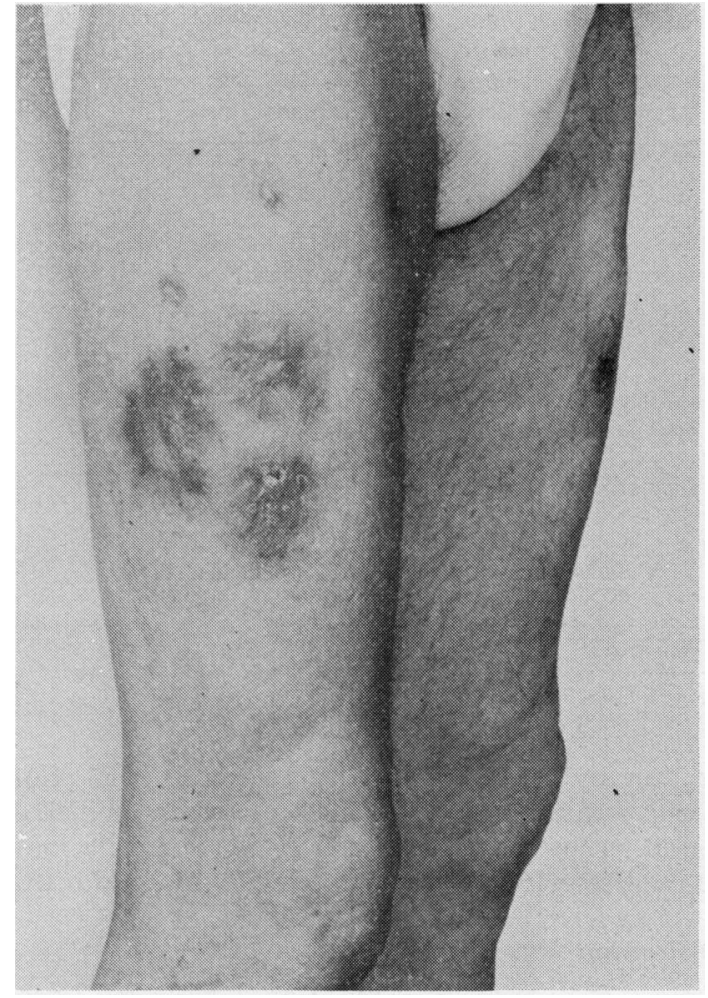

Fig 3 Scars resulting from healing of these ulcers one year after immunotherapy.

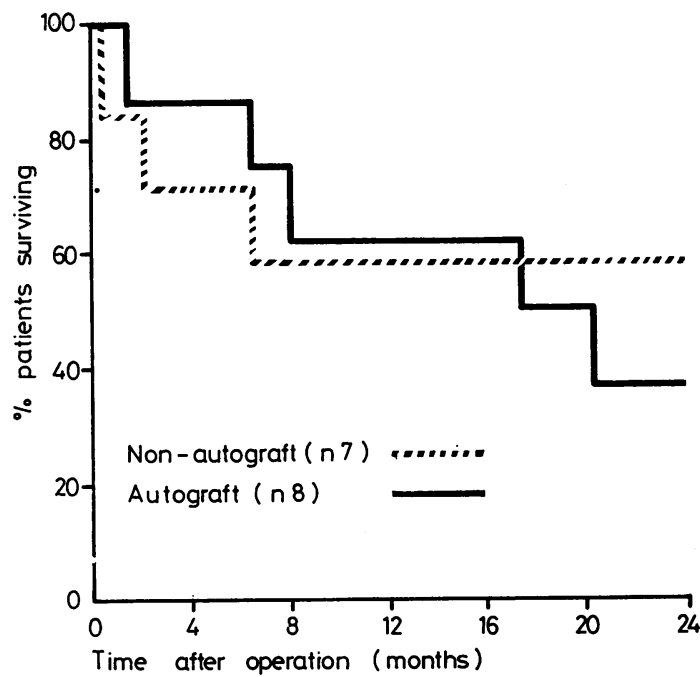

Fig 4 Survival graph for autograft and non-autograft patients. 
Table 3 Mean change in total leucocytes, total lymphocytes, and tuberculin test two weeks after operation from values recorded before operation in pilot trial

\begin{tabular}{llllll}
\hline & \multicolumn{2}{c}{ Autograft patients (8) } & \multicolumn{2}{l}{$\begin{array}{l}\text { Non-autograft } \\
\text { patients (7) }\end{array}$} \\
\cline { 2 - 3 } \cline { 5 - 6 } & Value & Significance* & & Value & Significance* \\
\hline $\begin{array}{c}\text { Change in total } \\
\text { leucocytes } \\
\text { (cells/cu mm) }\end{array}$ & +2388 & $\mathrm{P}=0.09$ & -783 & $\mathrm{NS}$ \\
$\begin{array}{c}\text { Change in total } \\
\text { lymphocytes } \\
\text { (cells/cu mm) }\end{array}$ & -271 & $\mathrm{NS}$ & -871 & $\mathrm{P}<0.05$ \\
$\begin{array}{c}\text { Change in } \\
\begin{array}{c}\text { T lymphocytes } \\
\text { (cells/cu mm) }\end{array}\end{array}$ & -279 & $\mathrm{NS}$ & -600 & $\mathrm{P}<0.05$ \\
$\begin{array}{c}\text { Change in } \\
\text { tuberculin } \\
\text { test (mm) }\end{array}$ & +6.4 & $\mathrm{P}=0.08$ & +0.5 & $\mathrm{NS}$ \\
\hline
\end{tabular}

$+=$ Increase $;-=$ Decrease.

${ }^{*} \mathrm{P}$ value assessed by Student's $t$ test or 2 sample Wilcoxon test.

NS $=$ Not significant.

mation by PPD was not measured in the pilot study, and the number of patients who completed radiotherapy was too small to allow conclusions to be drawn from subsequent immunological tests.

\section{Discussion}

In several reports of immunotherapy in resectable bronchial carcinoma the clinical results have been encouraging, but there has been little or no evidence that the treatment has produced any immunological response (Study Group for Bronchogenic Carcinoma, 1975; McKneally et al, 1976). A possible reason for this is the wide variation and technical difficulty of laboratory tests available. We have tried to overcome this by using a wide range of tests. A second problem is that cellmediated immunity decreases with age and intercurrent illness (Barnes et al, 1975), and we have allowed for this by using age- and sex-matched controls for the skin tests and controls over the age of $\mathbf{4 0}$ for the laboratory tests.

There was a similar frequency of positive tuberculin tests in patients with resectable bronchial carcinoma and in age- and sex-matched controls from the same area. Sensitisation to DNCB, however, was much less frequent in the carcinoma patients. These two findings have been taken to indicate impairment of the surveillance component of the immunological response (Holmes and Golub, 1976).

Results of preoperative lymphocyte transformation by PPD have not been previously reported, although Gross and Eddie-Quartey (1976) found lower mean values in 14 patients with bronchia carcinoma, of whom nine had been treated with radiotherapy. Our finding of depressed lymphocyte transformation by PPD with normal cutaneous tuberculin reactivity suggests that the former tes? is the more sensitive index of tuberculin reactivity

Tuberculin reactivity increased two weeks afte 5 resection of bronchial carcinoma followed by injection of irradiated autologous cells and BCG $\vec{\omega}$ Thus intradermal BCG overcame the normal post operative depression of tuberculin reactivity (Ban $\times$ cewicz et al, 1973). In contrast the postoperative depression of lymphocyte transformation by $\mathrm{PHA}-$ observed by Park et al (1971) was not found irbo either group. In that study, however, depressiorg did not persist for more than one week, whereas. the first postoperative measurement in our study, was made after two weeks.

The number of patients in this pilot study was too small to allow confident conclusions about the therapeutic effect of specific immunotherapy in bronchial carcinoma, but at the present stage it has not produced any improvement in survival of delay in tumour recurrence. Edwards and Whito well (1978) using BCG alone in a single subderma injection of $5 \times 10^{6}$ units also failed to increase्दे the survival of patients with resectable tumours $\frac{\mathbb{Q}}{\mathbb{D}}$ In contrast, McKneally et al (1976) found a sig $\cong$ nificant reduction in the incidence of tumour re를 currence among patients treated with intrapleura $\vec{P}$ BCG. In the only trial of irradiated tumour cele injections in bronchial carcinoma so far reported. the numbers in the operable group were too small to allow a definite conclusion of its effectiveness to be reached (Oldham et al, 1976).

The skin lesions produced by intradermal BCGं caused considerable suffering and delay in return. to work. Moreover, patients were too weak to tolerate the extra burden of daily radiotherapy three weeks after operation. Because of this, BCG is now being given percutaneously and post $\frac{P}{O}$ operative radiotherapy has been omitted from the treatment regimen in a further trial which is now in progress.

This work was supported by a grant from thew Cancer Research Campaign. We thank Mrs Margaret A Horsfield for administering the trialo Mr J R Cowie and nursing staff of the cardiothoracic unit, Mearnskirk Hospital, for help with ${ }^{+}$ the care of the patients, and Mrs J C Paton and Mrs S Wilson for secretarial help. We are also $\frac{\vec{D}}{\mathrm{~d}}$ most grateful to Dr J A Cameron for reading? tuberculin tests, to Dr Margaret M Hutton and the haematology department of the Victoria Ind firmary, and Dr N P Lucie and the haematologyo

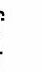


department of the Western Infirmary for estimating the total lymphocyte counts, and to $\mathrm{Mr} \mathrm{J} \mathrm{B}$ Forrester for help with the immunological tests.

\section{References}

Anderson, J M, Kelly, F, Wood, S E, Rodger, K D, and Freshney, R I (1973). Evaluation of leucocyte functions six years after tumour autograft in human mammary cancer. British Journal of Cancer, 28, suppl I, 83-96.

Bancewicz, J, Gray, A C, and Lindop, G (1973). The immunosuppressive effect of surgery-a possible mechanism. British Journal of Surgery, 60, 314-315.

Barnes, E W, Farmer, A, Penhale, W J, Irvine, W J, Roscoe, P, and Horne, N W (1975). Phytohaemagglutinin-induced lymphocyte transformation in newly presenting patients with primary carcinoma of the lung. Cancer, 36, 187-193.

Coy, P, Thomas, J W, and Hasham, N (1977). Lymphocyte transformation in lung cancer patients. Journal of the Canadian Association of Radiologists. 28, 43-48.

Dellon, A L, Potvin, C, and Chretien, P B (1975). Thymus-dependent lymphocyte levels in bronchogenic carcinoma: correlations with histology, clinical stage and clinical course after surgical treatment. Cancer, 35, 687-694.

Edwards, F R, and Whitwell, F (1978). Use of BCG as an immunostimulant in the surgical treatment of carcinoma of lung: a five-year follow-up report. Thorax, 33, 250-252.
Gross, N J, and Eddie-Quartey, A C (1976). Monitoring of immunological status of patients receiving BCG therapy for malignant disease. Cancer, 37, 2183-2193.

Holmes, E C, and Golub, S H (1976). Immunologic defects in lung cancer patients. The Journal of Thoracic and Cardiovascular Surgery, 71, 161-168.

Mackie, R, Sless, F R, Cochran, R, and de Sousa, M (1976). Lymphocyte abnormalities in mycosis fungoides. British Journal of Dermatology, 94, 173-178.

McKneally, M F, Maver, C, and Kausel, H W (1976). Regional immunotherapy of lung cancer with intrapleural BCG. Lancet, 1, 377-379.

Oldham, R K, Weese, J L, Herberman, R B, Perlin, E, Mills, M, Heims, W, Blom, J, Green, D, Reid, J, Bellinger, S, Law, I, McCoy, J, Dean, J H, Cannon, G B, and Djeu, J (1976). Immunological monitoring and immunotherapy in carcinoma of the lung. International Journal of Cancer, 18, 739-749.

Park, S K, Brody, J I, Wallace, H A, and Blakemore, W S (1971). Immunosuppressive effect of surgery. Lancet, 1, 53-55.

Price Evans, D A (1976). Immunology of bronchial carcinoma. Thorax, 31, 493-506.

Study Group for Bronchogenic Carcinoma (1975). Immunopotentiation with levamisole in resectable bronchogenic carcinoma: a double-blind controlled trial. British Medical Journal, 3, 461-464.

Requests for reprints to: Dr B H R Stack, Western Infirmary, Glasgow. 